\title{
An extinction cue reduces spontaneous recovery of a conditioned taste aversion
}

\author{
DOUGLAS C. BROOKS, MATTHEW I. PALMATIER, \\ ELISEO O. GARCIA, and JESSICA L. JOHNSON \\ California State University, Fresno, Califormia
}

\begin{abstract}
The effect of an auditory cue presented during extinction on spontaneous recovery of a conditioned taste aversion was investigated in three experiments. Experiment 1 demonstrated that the presence of the cue during extinction did not influence saccharin consumption during that phase, and that an aversion to saccharin in the absence of the cue was stronger at 18 days than at 1 day after extinction, representing spontaneous recovery rather than a renewal effect. Experiment 2 showed that a cue presented during extinction and testing reduced spontaneous recovery. Experiment 3 replicated that effect and showed that it depended on the cue's correlation with extinction and not on an unconditioned effect; cues that had been presented during or prior to conditioning did not reduce spontaneous recovery when presented during testing. The cue's potential to reduce spontaneous recovery through conditioned inhibition or configural cue learning is discussed, as is the possibility that the cue retrieves a saccharin extinction memory in a manner consistent with Bouton's (1993) account of spontaneous recovery.
\end{abstract}

Spontaneous recovery is the return of an extinguished conditioned response (CR) that typically occurs to a conditioned stimulus (CS) when the CS is presented after a retention interval elapses between extinction and testing. Until recently, spontaneous recovery had not been clearly demonstrated in the conditioned taste aversion (CTA) literature although the effect was demonstrated reliably in other conditioning preparations (e.g., conditioned emotional response, autoshaping, magazine entry, etc.; e.g., Brooks \& Bouton, 1993; Burdick \& James, 1970; Ellson, 1939; Lewis, 1956; Pavlov, 1927; Rescorla, 1997; Rescorla \& Cunningham, 1978; Robbins, 1990; Thomas \& Sherman, 1986). Kraemer and Spear (1992) found spontaneous recovery in CTA only after generalized, but not ordinary, extinction; that is, recovery occurred when the extinguished flavor was different from the one conditioned and tested. Recently, however, Rosas and Bouton (1996) demonstrated a reliable spontaneous recovery effect in CTA when the same flavor was used during conditioning, extinction, and testing. In three experiments, a saccharin aversion was conditioned in one trial and extinguished over three trials. Spontaneous recovery of the aversion to saccharin was shown consistently after an 18 day retention interval. The stronger aversion to saccharin during testing was due to the passage of time following extinction rather than to a change in the unconditioned preference for saccharin during the retention interval or to an increase in the aversion to saccharin after simply

This research was supported by grants from the California State University, Fresno. We thank Juan M. Rosas and two anonymous reviewers for helpful comments. Correspondence concerning this article should be addressed to D. C. Brooks, Department of Psychology, California State University, 5310 N. Campus Drive, Fresno, CA 93740 (e-mail: codyb(a)csufresno.edu). conditioning a moderate or strong aversion (i.e., without extinction). Rosas and Bouton's (1996) experiments likely provide the clearest demonstrations of spontaneous recovery in CTA to date (see also Rosas \& Bouton, 1997).

Most contemporary theories of associative learning are silent about the effects of retention intervals on performance, and therefore do not provide an explanation of effects such as spontaneous recovery (e.g., Mackintosh, 1975; Pearce, 1987; Pearce \& Hall, 1980; Rescorla \& Wagner, 1972; Wagner, 1981). A memory retrieval view (Bouton, 1991, 1993), however, does address the effects of retention intervals. On this view, conditioning and extinction result in the formation of different associations involving the CS and the unconditioned stimulus (US). Conditioning produces a CS-US association; extinction produces a separate CS-no-US association. Both of these associations, or memories, are available after extinction but are differentially accessible. Spontaneous recovery and some other postextinction CR-recovery effects (e.g., renewal) occur because of a failure to retrieve the CSno-US association that forms during extinction (the extinction memory). Bouton has suggested that the passage of time following extinction may serve as a gradually changing context. When the temporal context changes from extinction, the result is an inability to retrieve the extinction memory; the result in performance is a stronger $\mathrm{CR}$ (spontaneous recovery).

Evidence for this view has come from appetitive conditioning experiments investigating the effect of extinction cues on postextinction recovery (spontaneous recovery and renewal; Brooks, in press; Brooks \& Bouton, 1993, 1994). Bouton's view predicts that a retrieval cue for the extinction memory should reduce spontaneous recovery if presented during testing. This prediction has been supported 
by the results of several experiments. For example, in one (Brooks \& Bouton, 1993, Experiment 2), a tone CS was first trained as a signal for food. The appetitive CR elicited by the tone was then extinguished by being presented without food. During extinction, a light-off cue was terminated $15 \mathrm{sec}$ before $75 \%$ of the tone trials. Spontaneous recovery of the extinguished CR occurred 6 days after extinction when the tone was presented alone. However, when the cue was presented during the spontaneous recovery test, the CR to the tone was reduced. Additional results (e.g., Brooks \& Bouton, 1993, Experiments 2-4) indicated that the extinction cue's ability to reduce spontaneous recovery was not due to an unconditioned or nonassociative effect, or to excitation or conditioned inhibition to the cue. The cue's effect depended on its correlation with extinction; other cues that had been presented at times other than extinction failed to reduce spontaneous recovery to the extent that the extinction cue did. The overall pattern of findings in appetitive conditioning supports the view that spontaneous recovery occurs because of a failure to retrieve the extinction memory (e.g., tone-no food); the extinction cue may retrieve that memory and reduce recovery (Bouton, 1993; see also Brooks \& Bouton, 1994).

If Bouton's memory retrieval account of spontaneous recovery has generality, it should account for recovery in aversive as well as appetitive conditioning, for example, in CTA. Spontaneous recovery in CTA may also result from a failure to retrieve an extinction memory (e.g., CS-no illness). Thus, an analogous effect to that obtained with extinction cues in appetitive conditioning should be expected in CTA. We therefore used procedures similar to those used by Rosas and Bouton (1996), but in addition presented a cue during extinction of the saccharin aversion in order to determine whether the cue reduced the strength of the aversion when it was presented on a spontaneous recovery test. Such an effect would support the generality of a retrieval view of spontaneous recovery by suggesting that recovery in both appetitive and aversive conditioning could be explained by similar memory processes (Bouton, 1993; Brooks \& Bouton, 1993, 1994). It would also provide another similarity between the conditioning and memory effects seen in CTA and those observed in more traditional Pavlovian conditioning preparations (cf. Rozin \& Kalat, 1971). The purpose of the present experiments was therefore to investigate whether an auditory cue presented during extinction could also reduce spontaneous recovery of a conditioned taste aversion.

\section{EXPERIMENT 1}

Experiment 1 had three objectives. One was to replicate the findings of Rosas and Bouton (1996) by showing spontaneous recovery of CTA after an 18-day retention interval. The second objective was to determine the effect on saccharin consumption of adding a cue (an extinction cue, ' specif ically the sound of a buzzer) during extinction. The cue might become a discriminative stimulus for safety during extinction; thus, during extinction, consumption might become greater in the presence of the cue. The third objective was to test saccharin consumption following extinction in the absence of the extinction cue. The buzzer extinction cue we used was presented for the duration of each saccharin extinction drink; hence, it resembled a contextual cue. Testing without the cue might produce a renewal effect. However, we intended to show that any difference in consumption between 1- and 18-day retention intervals was due to the passage of time and not to testing without the extinction cue. The design is shown in Table 1. Four groups of rats received conditioning, extinction, and spontaneous recovery testing with a saccharin CS. All groups initially received access to saccharin followed by a $\mathrm{LiCl}$ injection. Then, during extinction, they received access to saccharin without $\mathrm{LiCl}$; in addition, Groups 18-Cue and 1-Cue received the cue for the duration of each extinction trial. Groups 18-No Cue and 1 -No Cue did not receive the cue. All groups were then tested for their aversion to saccharin alone (i.e., in the absence of the cue). Groups 1-No Cue and 1-Cue were tested 1 day after the final extinction trial. Groups $18-$ No Cue and $18-$ Cue were tested 18 days after that trial. The nocue groups were expected to demonstrate spontaneous recovery (Rosas \& Bouton, 1996), which would take the form of less consumption in Group 18-No Cue than in Group 1-No Cue. If an increase in saccharin aversion on the test depended on the passage of time rather than on renewal or loss of stimulus control during testing, the cue groups should show a similar pattern, with less consumption in Group 18-Cue than in Group 1-Cue.

\section{Method}

Animals and Apparatus. The subjects were 32 naive female Wistar rats bred at the California State University, Fresno (CSUF). They were approximately 100 days old and ranged in weight from 250 to $350 \mathrm{~g}$ at the start of the experiment. They were individually housed in suspended wire cages in a room maintained on a 14:10$\mathrm{h}$ light:dark cycle; the light part of the cycle began at $0630 \mathrm{~h}$. Food was available in the cages throughout the experiment.

A room adjacent to the colony room was used for all saccharin presentations. It contained a table with eight drinking boxes on it. Each drinking box was made of stainless steel and measured $19 \times$ $24 \times 14 \mathrm{~cm}$. The lid of each box had ventilation slots and a hole cut in it to accommodate a drinking tube. Illumination was provided by four standard $60-\mathrm{W}$ bulbs, each centered between every two boxes and positioned approximately $50 \mathrm{~cm}$ above the lids of the boxes. A $55-\mathrm{dB}$ fan provided masking noise. The CS flavor was a $0.05 \%$ sodium saccharin (EM Science, Gibbstown, NJ) solution mixed in distilled water. Illness was induced by a $0.3 \mathrm{M} 1 \% \mathrm{w} / \mathrm{v}$ intraperitoneal injection of lithium chloride ( $\mathrm{LiCl}$; EM Science, Gibbstown, NJ) also mixed with distilled water. The auditory cue was provided by four buzzers ( $65 \mathrm{~dB}$; Radio Shack, Fort Worth, TX), which produced multiple frequencies averaging approximately $500 \mathrm{~Hz}$; each buzzer was centered between every two boxes and positioned approximately $56 \mathrm{~cm}$ above the lid of the boxes. Fluids were administered at room temperature from $30-\mathrm{ml}$ plastic syringes, each fitted with a stainless steel drinking spout that protruded approximately $5 \mathrm{~cm}$ into the experimental box.

Procedure. The experiment was run on consecutive days. All drinking sessions used distilled water and were $15 \mathrm{~min}$ in duration. Each rat received two drinking sessions per day; the first began at 
Table 1

Design of Experiments 1-3

\begin{tabular}{|c|c|c|c|c|c|}
\hline Group & Pre & Conditioning & Extinction & Retention Interval & Test \\
\hline \multicolumn{6}{|c|}{ Experiment 1} \\
\hline 18-Cue & & Sacct & B: Sacc- & 18 days & Sacc- \\
\hline 18-No Cue & & Sacct & Sacc- & 18 days & Sacc- \\
\hline 1-Cue & & Sacct & B: Sacc- & 1 day & $\mathrm{Sacc}-$ \\
\hline 1-No Cue & & Sacct & Sacc- & 1 day & Sacc- \\
\hline \multicolumn{6}{|c|}{ Experiment 2} \\
\hline 18-Cue & & Sacc $t$ & B: Sacc- & 18 days & B: Sacc- \\
\hline 18-No Cue & & Sacc + & B: Sacc- & 18 days & $\mathrm{Sacc}-$ \\
\hline 1-Cue & & Sacct & B: Sacc- & 1 day & B: Sacc- \\
\hline 1-No Cue & & Sacc + & B: Sacc- & 1 day & $\mathrm{Sacc}-$ \\
\hline \multicolumn{6}{|c|}{ Experiment 3} \\
\hline Ext Cue & water & Sacc+ & B: Sacc - & 18 days & B: Sacc- \\
\hline No Cue & water & Sacct & B: Sacc- & 18 days & Sacc- \\
\hline Cond Cue & water & B: Sacc + & Sacc- & 18 days & B: Sacc- \\
\hline Neut Cue & B: water & Sacct & Sacc- & 18 days & B: Sacc- \\
\hline
\end{tabular}

Note-Sacc, saccharin; B, the auditory buzzer cue; a "+" indicates the LiCl US; a "-" indicates no US.

approximately $0730 \mathrm{~h}$ and the second at approximately $1730 \mathrm{~h}$ (a 10-h separation). The second drinking session simply involved access to water in the colony room. Hereafter, only the first drinking session of each day is described.

On the first 7 days, all rats received water. On the first 4 of those days, the water was given in the colony room; on the next 3 days, the water was given in the drinking boxes. The rats were then divided into four groups $(n s=8)$ counterbalanced for water intake during those 7 days.

Beginning the next day, Groups 18-Cue and 18-No Cue received conditioning, extinction, and then the 18-day retention interval before testing. On the conditioning day, within 10 min after receiving 15-min access to saccharin, these groups were given injections of $\mathrm{LiCl}$. The injections were given in the corridor outside the room that contained the drinking boxes. Immediately following the injection, each rat was replaced in its drink box for approximately $5 \mathrm{~min}$ (with no fluids available) and then returned to its cage in the colony room. On the day after conditioning, each rat recejved water in the colony room (a recovery day). On each of the next 3 days, Groups 18-Cue and 18-No Cue received access to saccharin for $15 \mathrm{~min}$ in the drinking boxes, but did not receive $\mathrm{LiCl}$; also, for Group 18 Cue, the buzzer cue was presented throughout each of these 15-min extinction sessions. For the next 15 days after the end of extinction, Groups 18-Cue and 18-No Cue received $15 \mathrm{~min}$ of access to water in the colony room. On the next 2 days, they received $15 \mathrm{~min}$ of access to water in the drinking boxes.

The conditioning and extinction phases for Groups 1-Cue and 1-No Cue began after extinction ended for Groups 18-Cue and $18-$ No Cue. Since the procedure was designed to equate the motivation to drink in all groups during testing, all four groups received the two-drinks-per-day schedule for the same total number of days prior to testing and all the groups were tested on the same days. Thus, Groups 1-Cue and 1-No Cue continued to receive access to water while, and for several days after, Groups 18-Cue and 18-No Cue received conditioning and extinction. The conditioning and extinction procedures for Groups 1-Cue and 1-No Cue were the same as for the other two groups. Group 1-Cue received the cue during each extinction session. Testing for Groups 1-Cue and 1-No Cue began the day after the last extinction trial; for Groups 18-Cue and 18-No Cue, it began the day after the last retention-interval exposure to water in the drinking boxes ( 18 days after the last extinction trial). Testing for all groups took place on the same 4 days, with each day involving 15 min of access to saccharin only.

In each experiment, the amount of fluid consumed was measured to the nearest milliliter and was evaluated using analysis of variance (ANOVA). Planned comparisons were conducted using the techniques discussed by Howell (1987, pp. 431-443). The rejection criterion was always set at $p<.05$.

\section{Results and Discussion}

The left panel of Figure 1 shows mean saccharin consumption for the four groups on the conditioning trial (Cond) and the three extinction trials (E1-E3). The right panel shows the two two-trial blocks of the spontaneous recovery test ( $\mathrm{T} 1$ and $\mathrm{T} 2$ ). There were no differences among the groups on the conditioning trial. A cue condition (extinction with or without the cue) $\times$ retention interval (testing 1 or 18 days after extinction) ANOVA revealed no significant effect of cue condition or retention interval and no interaction of these factors $[F \mathrm{~s}(1,28)<$ $1.56, p \mathrm{~s}>.22]$. There were also no differences among the groups during extinction. A cue condition $\times$ retention interval $x$ trial ANOVA on the three extinction trials revealed a significant trial effect $[F(2,56)=92.02]$ but no cue condition or retention interval effect and no interactions $(F \mathrm{~s}<1)$. The groups also did not differ on the last extinction trial $(F \mathrm{~s}<1)$.

A cue condition $\times$ retention interval ANOVA of the first two-trial block of the test revealed an effect of retention interval $[F(1,28)=21.54]$ but no effect of cue condition and no interaction $(F s<1)$. Comparisons revealed that the no-cue groups differed, with Group 18-No Cue drinking less saccharin than Group 1-No Cue $[F(1,28)=$ 15.13]. The cue groups showed a similar pattern, with Group 18-Cue drinking less saccharin than Group 1-Cue $[F(1,28)=7.15]$. The groups tested at 1 day did not differ from one another, nor did the groups tested at 18 days 


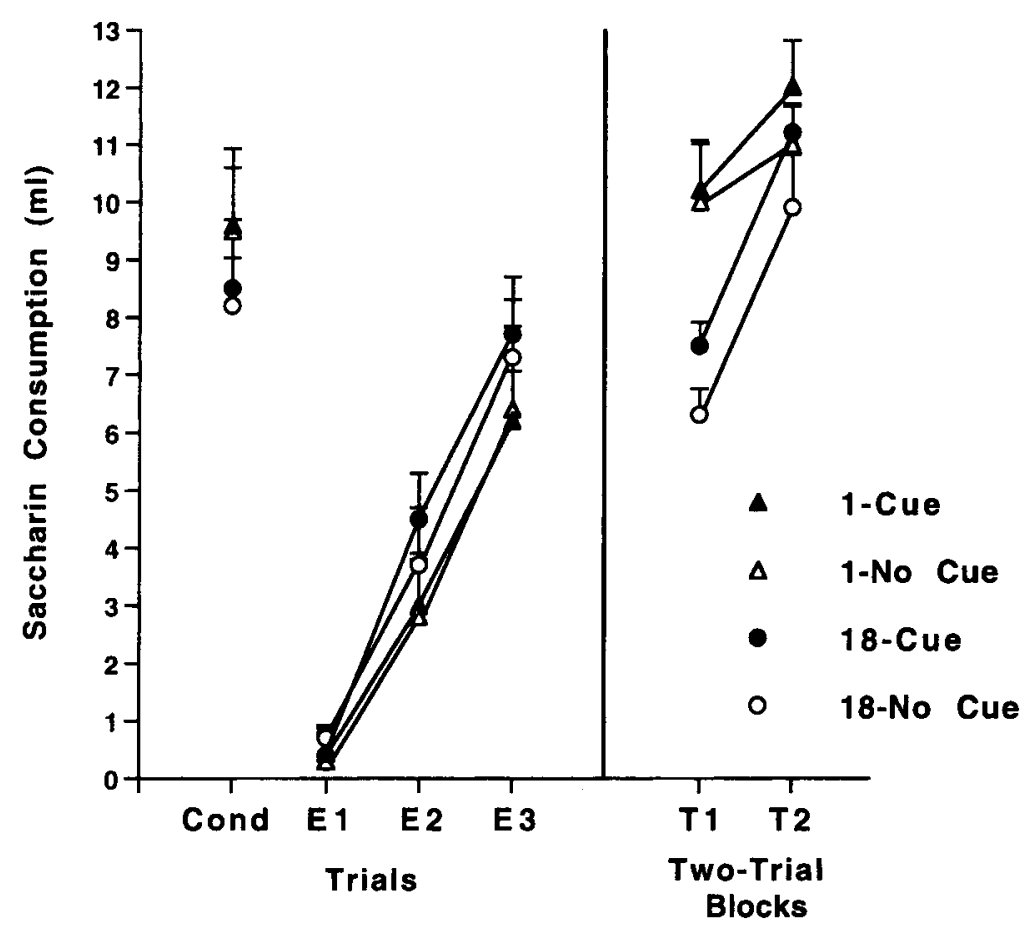

Figure 1. Group mean saccharin consumption on the conditioning trial (Cond), the three extinction trials (E1-E3), and the two two-trial blocks of the spontaneous recovery test (T1-T2) in Experiment 1.

$\left[F_{\mathrm{s}}(1,28)<1.64, p \mathrm{~s}>.21\right]$. There were no differences on the second two-trial block of the test $\left(F_{\mathrm{S}}<1\right)$.

There was no evidence that presenting the cue during extinction influenced saccharin consumption during extinction or testing. Furthermore, the decrease in saccharin consumption observed at 18 days (by comparing the cue groups) appears to be due to the passage of time rather than to a renewal effect or loss of stimulus control by the extinction cue produced by testing without the cue. Thus, the difference in saccharin consumption during testing between the no-cue groups, and also between the cue groups, represents spontaneous recovery. This replicates the findings of Rosas and Bouton (1996, Experiments 1-3) by showing spontaneous recovery of an extinguished saccharin aversion with an 18-day retention interval. These results suggest that spontaneous recovery may occur reliably in CTA, at least under conditions similar to those used here (see Rosas \& Bouton, 1996).

The absence of a renewal effect on testing without the extinction cue, which has also been found in appetitive conditioning (e.g., Brooks \& Bouton, 1993, 1994), is most likely due to strong retrieval of the extinction memory involving saccharin by the saccharin CS itself soon after extinction. Retrieval of extinction by the CS at that time is strong whether extinction occurred with or without the cue. Different types and/or sets of cues present during extinction, however, may produce renewal effects in CTA (cf. Rosas \& Bouton, 1997, 1998).

\section{EXPERIMENT 2}

Having demonstrated spontaneous recovery at an 18day interval and also that the extinction cue does not influence saccharin consumption during extinction, a second experiment provided an initial investigation of the effect of the cue when it is presented during spontaneous recovery testing. The design is shown in Table 1. There were four groups of rats that received conditioning, extinction, and spontaneous recovery testing with saccharin. All groups initially received access to saccharin followed by a $\mathrm{LiCl}$ injection. They then received access to saccharin without $\mathrm{LiCl}$ (extinction). During extinction, all groups received the extinction cue for the duration of each extinction trial. The groups were then tested for their aversion to saccharin. Groups 1-Cue and 1-No Cue were tested 1 day after the final extinction trial; Groups 18-Cue and $18-$ No Cue were tested 18 days after extinction. In this experiment, the group designations refer to whether the cue was or was not presented during testing. Groups 18-No Cue and 1-No Cue were expected to demonstrate spontaneous recovery just as had the identically treated groups that received the cue only during extinction in Experiment 1. Of greatest interest was Group 18-Cue. If a cue presented during extinction could reduce spontaneous recovery of a conditioned taste aversion during testing, Group 18-Cue should consume more saccharin than Group 18-No Cue. 


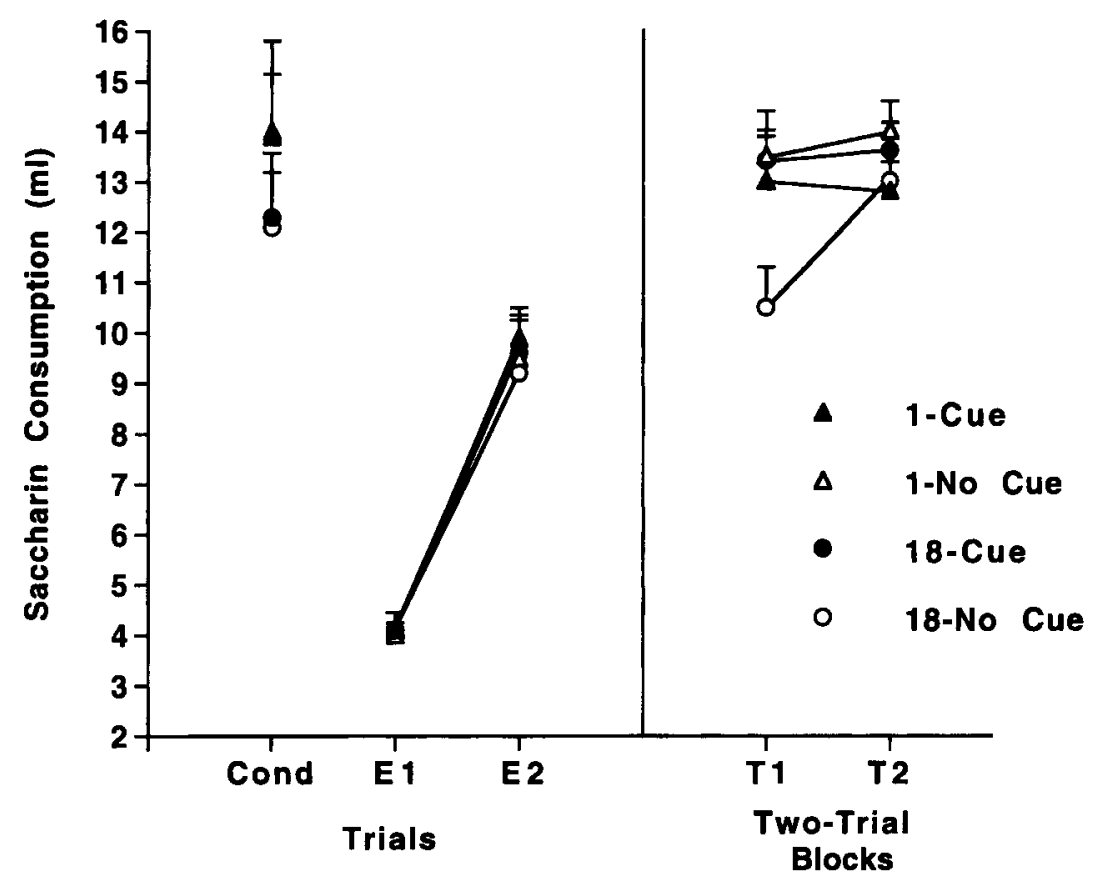

Figure 2. Group mean saccharin consumption on the conditioning trial (Cond), the two extinction trials ( $\mathrm{E} 1$ and $\mathrm{E2}$ ), and the two two-trial blocks of the spontaneous recovery test (T1-T2) in Experiment 2.

\section{Method}

Animals and Apparatus. The subjects were 32 naive female Sprague-Dawley rats bred at CSUF. They were approximately 150 days old and ranged in weight from 220 to $300 \mathrm{~g}$ at the start of the experiment. Maintenance conditions and apparatus were the same as in Experiment 1.

Procedure. The experiment was run on consecutive days. The drinking schedule was as in Experiment 1; the second drinking session of each day was always water, and so only the first drinking session of each day is described. On the first 6 days, all rats received access to water. On the first 2 of those days, the water was presented in the colony room; on the next 4 days, water was presented in the drinking boxes. The rats were then divided into four groups $(n s=8)$ counterbalanced for water intake during these 6 days.

Beginning on the next day, Groups 18-Cue and 18-No Cue received conditioning, extinction, and then the 18-day retention interval before testing. On the conditioning day, they received access to saccharin followed by an injection of $\mathrm{LiCl}$. The day after conditioning was a recovery day, with water access in the home cage. On each of the next 2 days, they received access to saccharin for $15 \mathrm{~min}$ in the drinking boxes but did not receive $\mathrm{LiCl}$; in addition, both groups received the buzzer cue throughout each extinction session. For the next 15 days after the end of extinction, they received $15 \mathrm{~min}$ of access to water in the colony room. On the last 2 days before testing, they received $15 \mathrm{~min}$ of access to water in the drinking boxes.

The conditioning and extinction phases for Groups 1-Cue and 1-No Cue began after extinction ended for Groups 18-Cue and 18-No Cue. As before, the procedure was designed to equate the motivation to drink in all groups during testing; all four groups received the two-drinks-per-day schedule for the same total number of days prior to testing, and all the groups were tested on the same days. Thus, Groups 1-Cue and $1-$ No Cue continued to receive water during, and for several days after, Groups 18-Cue and 18-No
Cue received conditioning and extinction. The conditioning and extinction procedures for Groups 1-Cue and 1-No Cue were the same as for the other two groups. Both Group 1-Cue and Group 1-No Cue received the cue during each extinction session. Testing for Groups 1-Cue and 1-No Cue began the day after the last extinction trial; for Groups 18-Cue and 18-No Cue, it began the day after the last retention interval session with water in the drinking boxes (18 days after the last extinction trial). Testing for all groups took place over the same 4 days; each day involved $15 \mathrm{~min}$ of access to saccharin. For Groups 18-Cue and 1-Cue, the cue was also presented throughout each of the 15 -min saccharin tests.

\section{Results and Discussion}

The left panel of Figure 2 shows mean saccharin consumption for the four groups on the conditioning trial (Cond) and the two extinction trials (E1 and E2). The right panel shows the two two-trial blocks of the spontaneous recovery test ( $\mathrm{T} 1$ and $\mathrm{T} 2$ ). There were no differences among the groups on the conditioning trial. A cue condition (testing with or without the extinction cue) $\times$ retention interval (testing 1 or 18 days after extinction) ANOVA revealed no significant effect of cue condition or retention interval and no interaction of these factors $\left[F_{s}(1,28)<1\right]$. There were no differences among the groups during extinction. A cue condition $\times$ retention interval $\times$ trial ANOVA of those trials revealed a trial effect $[F(1,28)=$ 73.90] but no cue condition or retention interval effect and no interactions $[F \mathrm{~s}(1,28)<1]$. The groups did not differ on the last extinction trial $(F \mathrm{~S}<1)$.

A cue condition $\times$ retention interval ANOVA of the first two-trial block of the test revealed no effect of cue 
condition or retention interval $\left[F_{\mathrm{s}}(1,28)<2.44, p \mathrm{~s}>.13\right]$. However, the cue condition $\times$ retention interval interaction was significant $[F(1,28)=4.61]$. Investigation of this interaction revealed that Group 18-No Cue consumed less saccharin than Group 1-No Cue $[F(1,28)=4.86]$, indicating spontaneous recovery of the saccharin aversion in Group 18-No Cue. In addition, Group 18-Cue consumed significantly more saccharin than Group 18-No Cue $[F(1,28)=5.57]$. Groups $1-$ Cue, $1-$ No Cue, and $18-$ Cue did not differ $(F \mathrm{~s}<1)$. There were no differences on the second two-trial block of the test $(F \mathrm{~s}<1)$.

The finding of less consumption by Group 18-No Cue than by Group 1-No Cue on the test replicates the spontaneous recovery effects shown in Experiment 1 . Of greatest interest here is the enhanced consumption in Group 18-Cue compared with that in Group 18-No Cue. The enhancement in Group 18-Cue indicates a reduction in spontaneous recovery of the saccharin aversion by a cue that had been presented during extinction. That result is analogous to the extinction cue effects reported by Brooks (in press; Brooks \& Bouton, 1993) in appetitive conditioning. The overall pattern of findings in appetitive conditioning is consistent with the view that a cue presented during extinction reduces spontaneous recovery by activating an otherwise inaccessible CS-no-US association that forms during extinction (i.e., the cue retrieves an extinction memory; Bouton, 1993, 1994; Brooks \& Bouton, 1993, 1994). The extinction cue in the present experiment may have reduced spontaneous recovery by activating that type of association involving saccharin (e.g., saccharin-no LiCl). Alternatively, the cue's effect during testing may have been due to an unconditioned effect by the cue that resulted in enhanced consumption on the test. This possibility was examined in Experiment 3.

\section{EXPERIMENT 3}

Experiment 3 had two objectives. The first was to replicate the effect of the extinction cue shown after the 18-day retention interval in Experiment 2. Therefore, as shown in Table 1, the treatment of Groups Ext Cue and No Cue was similar to that of Groups 18-Cue and 18-No Cue from Experiment 2. After receiving water drinks for several days, Groups Ext Cue and No Cue both received conditioning and extinction with saccharin with the cue present during extinction. Both of these groups were tested 18 days after extinction; during testing, the cue was presented to Group Ext Cue but not to Group No Cue. As in Experiment 2, the extinction cue was expected to reduce the aversion to saccharin in Group Ext Cue in comparison with Group No Cue.

The other objective of Experiment 3 was to investigate whether a cue's effect on spontaneous recovery depended on its correlation with extinction. Because of that correlation, the extinction cue in Experiment 2 may have retrieved an inaccessible extinction memory during testing.
Alternatively, it might have had such an unconditioned effect such as enhancing generalization decrement between training and testing, which might have decreased the conditioned aversion and resulted in enhanced consumption on the test. If any cue present during the spontaneous recovery test can reduce the measure of aversion to saccharin through an unconditioned effect, then a cue presented during a phase other than extinction and then again during testing should produce enhancement to the same extent as the extinction cue. To evaluate the possibility of such an unconditioned effect, we compared the effect of a cue that was presented prior to conditioning with the effect of the extinction cue. Group Neut Cue received the cue along with access to water on the 3 days prior to conditioning. This cue was not correlated with conditioning or extinction of the saccharin aversion in Group Neut Cue, so we expected it to be associatively neutral. Eighteen days after extinction, Group Neut Cue was also tested for its aversion to saccharin and the cue was presented during testing. If any cue can produce an unconditioned enhancement of consumption on the test, Group Neut Cue should consume as much saccharin as Group Ext Cue, and those two groups should have a weaker aversion than Group No Cue. However, if a cue's ability to reduce the saccharin aversion depends on its correlation with extinction, only Group Ext Cue should have a weaker aversion than Group No Cue.

We also tested the effect of a cue presented during conditioning. Group Cond Cue received saccharin conditioning, extinction, and testing at the same times as the other groups. For this group, however, the cue was presented during saccharin conditioning rather than prior to conditioning or during extinction. The cue was presented again during testing. In appetitive conditioning, Brooks and Bouton $(1993,1994)$ found that a cue presented during conditioning and then during tests for spontaneous recovery and renewal did not influence test performance as compared with conditions involving testing with no cue (i.e., the cue presented during conditioning did not enhance spontaneous recovery or renewal). In the present experiment, those findings alone lead to the prediction that Groups Cond Cue and No Cue should not differ during testing. In Brooks and Bouton's experiments, however, the cue correlated with conditioning was presented only during the last approximately one fifth of the CSconditioning trials (i.e., after the CR had already reached a near-asymptotic level). In the present design, Group Cond Cue received the cue during the only conditioning trial, a procedure that many theories predict should endow the cue with associative strength (e.g., Mackintosh, 1975; Pearce \& Hall, 1980; Rescorla \& Wagner, 1972). However, because illness may be more readily associated with flavor than with auditory stimuli (e.g., Garcia, 1989; Garcia \& Koelling, 1966), we expected that the cue presented during conditioning would be unlikely to enter into a direct association with the US during conditioning, and 
could therefore serve as an additional control for nonassociative effects of a cue presented during testing.

\section{Method}

Animals and Apparatus. The subjects were 32 male Wistar rats bred at CSUF. They were approximately 110 days old and ranged in weight from 300 to $400 \mathrm{~g}$ at the start of the experiment. Maintenance conditions and apparatus were the same as in the previous experiments.

Procedure. The experiment was run on consecutive days. The drinking schedule was as before; the second drinking session of each day was always with water, and so only the first drinking session of each day is described. On the first 5 days, all rats received access to water. On the first 3 of those days, the water was presented in the colony room; on the next 2 days, water was presented in the drinking boxes. The rats were then divided into four groups $(n \mathrm{~s}=8)$ counterbalanced for water intake during these 5 days.

The experimental design equated all of the groups on exposure to the cue prior to testing. On each of the next 3 days, all rats received $15 \mathrm{~min}$ of access to water in the drinking boxes; on these days, Group Neut Cue received the cue during each drink. All the rats then received conditioning involving access to saccharin for 15 min followed by a $\mathrm{LiCl}$ injection. For Group Cond Cue, the cue was presented during the 15 min of saccharin access, and also during two 15 -min periods just after the $\mathrm{LiCl}$ injection. The two postinjection cue periods were separated by $5 \mathrm{~min}$, during which the cue was off; the rats remained in the boxes for the entire 35-min postinjection period. To equate exposure to the boxes for all groups during conditioning, the other three groups received the same conditioning and postinjection treatment as Group Cond Cue, except that the cue was not presented. On the day after conditioning, each rat received water in the colony room (a recovery day). On each of the next 3 days, all rats received 15 min of access to saccharin without $\mathrm{LiCl}$ (extinction); for Groups Ext Cue and No Cue, the cue was also presented throughout each of those drinks. One rat from each of Groups Cond Cue and Ext Cue and 2 from Group No Cue failed to show evidence of extinction; their data were eliminated from the study (the resulting $n s=7,7$, and 6 , respectively).

All groups received an 18-day retention interval after extinction. For the first 15 days, all rats received $15 \mathrm{~min}$ of access to water in the colony room. On the next 2 days, they received $15 \mathrm{~min}$ of access to water in the drinking boxes. Testing took place beginning the next day for all groups. On each of the 4 test days, each group received access to saccharin for $15 \mathrm{~min}$. Group No Cue received only saccharin; the other groups also received the cue throughout each 15-min drink.

\section{Results and Disc:ission}

The left portion of Figure 3 shows the mean water consumption for the four groups averaged over the 3 days on which Group Neut Cue received exposure to the cue (Pre). The center portion shows mean saccharin consumption for the groups on the conditioning trial (Cond) and on the three extinction trials (E1-E3). The right portion shows the two two-trial blocks of the spontaneous recovery test (T1 and $\mathrm{T} 2$ ). The groups did not differ on fluid consumption prior to or during conditioning or during extinction, and the cue did not influence fluid consumption during these phases. There were no differences in water consumption on the days Group Neut Cue received the cue (Pre). An ANOVA of the means from those days revealed no effect of group $[F(3,24)<1.08, p<$ $.30]$; presenting the cue to Group Neut Cue did not affect water consumption during this phase. The groups did not differ on the conditioning trial $[F(3,24)<1]$, indicating that presenting the cue to Group Cond Cue did not influence saccharin consumption during conditioning. There were also no differences among the groups during extinction. A group $\times$ trial ANOVA on the three extinction trials revealed a trial effect $[F(3,24)=125.57]$ but no group effect $[F(3,24)<2.44, p>.08]$ and no interaction $[F(3,24)<1]$, indicating that presentation of the cue to Groups Ext Cue and No Cue did not influence saccharin consumption during extinction and that access to saccharin without the cue in Group Cond Cue did not appreciably influence the aversion to saccharin during extinction (cf. Archer, Sjödén, \& Nilsson, 1985; Puente, Cannon, Best, \& Carrell, 1988). The groups did not differ on saccharin consumption on the last extinction trial [group $F(3,24)<2.19, p>.13$ ]

On the first test block, Group Ext Cue consumed more saccharin than the other three groups. On the second test block, Group Ext Cue continued to drink more than Groups No Cue and Cond Cue. In addition, Groups No Cue and Neut Cue increased their consumption of saccharin more than did Group Cond Cue. An ANOVA of the first two-trial block of the test revealed a main effect of group $[F(3,24)=4.47]$. Comparisons revealed that Group Ext Cue consumed more saccharin than did Group No Cue $[F(1,24)=11.64]$, indicating that presenting the extinction cue reduced spontaneous recovery of the saccharin aversion. Group Ext Cue also consumed more saccharin than did both Groups Cond Cue and Neut Cue $[F s(1,24)>$ 4.59 , ps $<.043]$. Groups No Cue, Cond Cue, and Neut Cue did not differ on the first test block $\left[F_{\mathrm{s}}(1,24)<3.24\right.$, $p$ s $>$.08]. An ANOVA of the second two-trial block of the test also revealed an effect of group $[F(3,24)=4.51]$. Comparisons revealed that Group Ext Cue again consumed significantly more saccharin than Group No Cue $[F(1,24)=8.57]$. Group Neut Cue did not differ from either Group Ext Cue or Group No Cue $\left[F_{\mathrm{s}}(1,24)<2.29\right.$, $p>.14]$. Interestingly, on the second test block, Group Cond Cue consumed significantly less saccharin than each of the other three groups $\left[F_{\mathrm{s}}(1,24)>6.78\right]$.

Saccharin consumption did not differ among the groups during the preconditioning, conditioning, or extinction phases, indicating that the cue did not influence drinking before the test. More importantly, as in Experiment 2, a cue featured during extinction reduced spontaneous recovery of the aversion to saccharin when that cue was presented during testing. Of central interest here was that the effect of the extinction cue on recovery depended on the cue's correlation with extinction; during testing, cues that had been presented during or prior to conditioning did not reduce the saccharin aversion compared with testing with no cue. These findings are consistent with Brooks and Bouton's (1993, 1994) earlier findings in appetitive conditioning which suggested that a cue's ability to reduce spontaneous recovery depended on its correlation with extinction rather than on an unconditioned process. Interestingly, as the test 


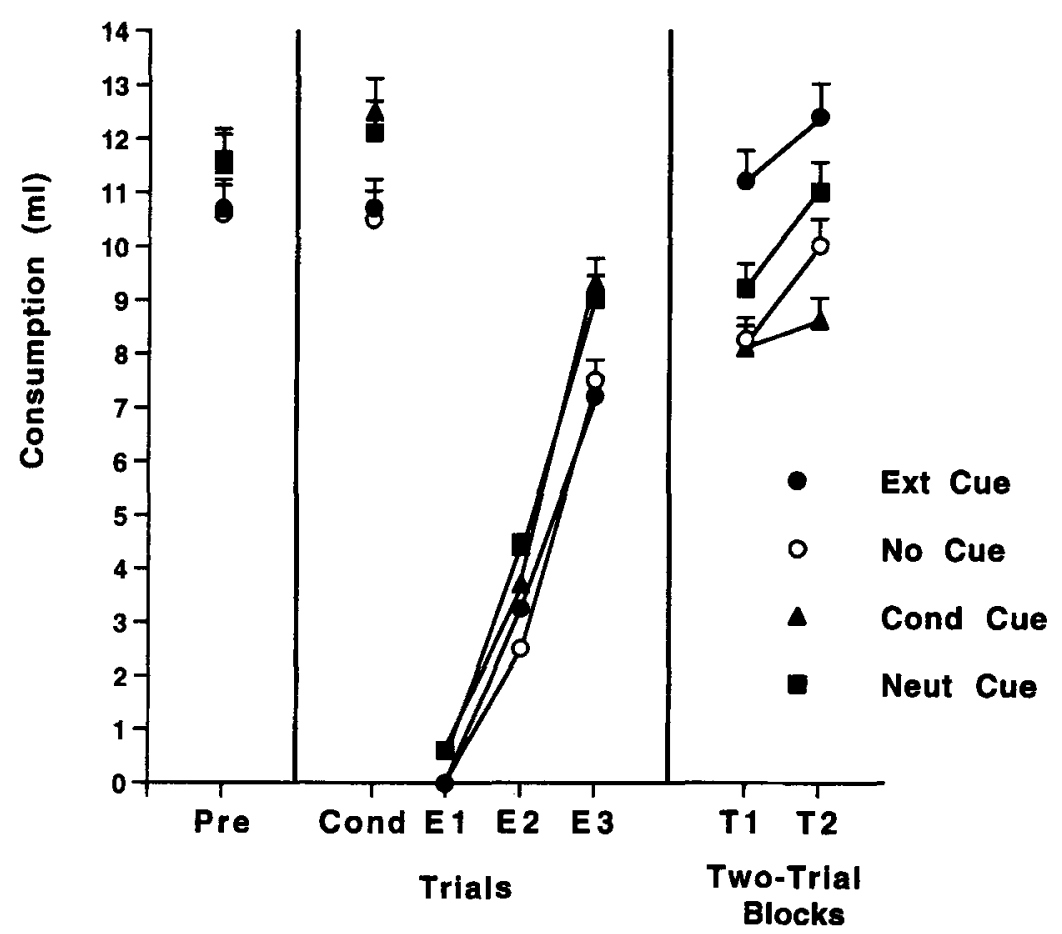

Figure 3. Group mean water consumption averaged over the 3 days on which Group Neut Cue received exposure to the cue and all of the groups received water (Pre) and mean saccharin consumption for the groups on the conditioning trial (Cond), the three extinction trials (E1-E3), and the two two-trial blocks of the spontaneous recovery test (T1-T2) in Experiment 3. For Groups Ext Cue, Cond Cue, and Neut Cue, the cue was presented in extinction, in conditioning, or prior to conditioning, respectively; each of those groups received the cue during testing.

progressed, the rats that had received a cue during conditioning (Group Cond Cue) maintained the strongest aversion to saccharin. For the present purpose, the crucial result with Group Cond Cue was that the cue presented during conditioning did not enhance saccharin consumption during testing. Because these experiments were centrally designed to investigate the extinction cue's effect on spontaneous recovery in CTA, we did not pursue the conditioning cue's effect here.

\section{GENERAL DISCUSSION}

These experiments investigated the effect of an auditory extinction cue on saccharin consumption in a spontaneous recovery paradigm. Spontaneous recovery of an extinguished saccharin aversion was demonstrated (Experiments 1-3), consistent with findings reported by Rosas and Bouton (1996). The decrease in saccharin consumption over the 18-day retention interval was unlikely to have been due to a loss of or change in stimulus control over drinking by the auditory cue that might have formed prior to testing. We found no evidence that the auditory cue influenced fluid consumption during extinction (Experiments 1 and 3 ) or prior to or during conditioning (Experiment 3 ). These recovery effects support the sugges- tion that spontaneous recovery can occur reliably in CTA under conditions similar to those used here (see also Rosas \& Bouton, 1996). It also adds support to the view that many effects in CTA parallel those obtained with other Pavlovian conditioning methods (cf. Garcia, Hankins, \& Rusiniak, 1974; Rozin \& Kalat, 1971).

Of greatest interest here is the finding that an auditory cue presented during saccharin extinction trials reduced spontaneous recovery of the aversion when that cue was presented during testing (Experiments 2 and 3 ). The consumption-increasing effect of the extinction cue is especially remarkable considering that an auditory cue might be expected to cause orienting or competing behaviors that might disrupt (i.e., decrease) consumption during testing. The recovery-reducing effect of the cue did not appear to be the result of an unconditioned effect such as generalization decrement; cues that had been presented either during or prior to conditioning did not attenuate spontaneous recovery when presented during the test (Experiment 3 ).

Experiments 1-3 do not rule out the possibility that the extinction cue reduced spontaneous recovery through conditioned inhibition (e.g., Rescorla, 1969). Evidence from other conditioning methods suggests that a stimulus can become inhibitory when presented in simultaneous compound with an extinguishing CS (i.e., the stimulus ap- 
pears to enter into a direct inhibitory association with the US; Cunningham, 1981; Rescorla, 1979; Rescorla \& Wagner, 1972). We have also conducted summation and retardation tests of the extinction cue used in Experiments $1-3$, in an attempt to evaluate conditioned inhibition. A summation test examined whether the extinction cue would reduce the conditioned aversion to another taste (vinegar). Two groups received conditioning and extinction with saccharin, with the cue presented during extinction just as in Experiments 1-3. Both groups then received separate conditioning with vinegar, followed by a five-trial summation test. During testing, one group received access to vinegar alone; the other received access to vinegar while the extinction cue was present. The groups did not differ during the test. Furthermore, at no point did the group that received vinegar and the cue consume more vinegar than the other group. This pattern and the observation that on the final test trial vinegar consumption in both groups was near asymptotic levels make it difficult to argue that the experiment lacked sufficient power to show potential conditioned inhibition to the extinction cue.

We also attempted a retardation test designed to determine whether an extinction cue aversion could condition more slowly than an aversion to a control cue that was not correlated with saccharin extinction. After two groups received saccharin conditioning, one group (Ret) received three cued saccharin extinction trials, while the other (the control group) received three cued water-drinking trials (without saccharin). Both groups then received the same treatment during a 7-day test. On Test Days 1, 3, 5, and 7, the cue was on during access to water; this was followed by a $\mathrm{LiCl}$ injection on Days 1, 3, and 5 . Days 2 and 4 were recovery days. These groups also did not differ at any point during the retardation test, suggesting that the cue's connection with extinction did not permit it to differentially influence performance during testing. A firm conclusion based on this test is difficult to reach because of well-known constraints on auditory stimulus-illness association formation (e.g., Garcia \& Koelling, 1966) which seem to pose a challenge to any retardation testing of auditory cues in CTA. (With some other designs, such associations may be expressed; cf. Holland, 1981.) Evidence for conditioned inhibition might have also come from an enhancement of fluid consumption during testing in Group Ret; some researchers have argued that a preference for certain stimuli in CTA experiments represents conditioned inhibition (see Best, 1975; Best, Dunn, Batson, Meachum, \& Nash, 1985; cf. Delamater, Kruse, Marlin, \& LoLordo, 1986). This might have occurred if consumptinn was not already at a ceiling at the beginning of testing. (There may have been potential for consumption during testing to exceed that in conditioning or at the end of extinction, as it did in the last block of testing in Experiment 1.) Nevertheless, there was no enhancement in Group Ret over that in the control group. Overall, the results from the summation and retardation tests provide no evidence that the extinction cue acquired the properties expected of a conditioned inhibitor. Nevertheless, because these are null results, we cannot unequivocally rule out conditioned inhibition.

The results from the groups tested at 18 days in Experiments 2 and 3 could be explained by using a configural account of the cues' effect on saccharin consumption (e.g., Pearce, 1987). During testing, the reconstitution of the extinction cue with saccharin promoted saccharin consumption analogous to consumption at the end of extinction, and the recombination of the conditioning cue and saccharin produced an increased aversion. However, a configural account predicts weaker extinction performance (increased saccharin aversion) when testing without the extinction cue, which was not found in Experiment 1 or with Groups 1-Cue and 1-No Cue in Experiment 2 (we suggest an explanation for this in the discussion of $\mathrm{Ex}$ periment 1 ).

The overall pattern of results with the extinction cue is analogous to that reported with extinction cue effects on spontaneous recovery in appetitive conditioning (e.g., Brooks, in press; Brooks \& Bouton, 1993). In the appetitive conditioning research, as in the present work, introducing a cue during extinction or conditioning did not influence performance to the CS during those phases. More important, the cue featured during extinction reduced spontaneous recovery in both preparations. And there was no evidence that cues initially presented outside extinction attenuated recovery. Thus, in neither preparation nor motivational system did the potential of the extinction cue to reduce spontaneous recovery result from an unconditioned effect on performance to the target CS. And in neither was there evidence that the extinction cue's ability to reduce recovery resulted from conditioned inhibition.

Taken together, the results from the present experiments and those from the appetitive conditioning studies indicate that an extinction cue's effect on spontaneous recovery may be fairly general, applying in both appetitive and aversive systems. Thus, an extinction cue may be expected to produce analogous effects in other preparations in which the motivational significance of the US is either aversive or appetitive (e.g., CER, nictitating membrane conditioning, autoshaping, drug conditioning). Furthermore, the cue's postextinction CR-attenuating properties in each motivational system may not be limited to spontaneous recovery. Brooks and Bouton (1994) found that an extinction cue reduced the renewal effect in appetitive conditioning. That finding along with the present ones and recent reports of renewal in CTA (e.g., Rosas \& Bouton, 1997) suggest that an extinction cue similar to the one used in the present experiments should also attenuate renewal in CTA.

A memory retrieval view (Bouton, 1993) can account for the spontaneous recovery and extinction cue effects reported here, as well as the analogous effects in appetitive conditioning (e.g., Brooks \& Bouton, 1993). Accord- 
ing to this view, conditioning results in one association, or memory, involving the CS (a CS-US memory), while extinction results in a separate association involving the CS (a CS-no-US memory). Several postextinction CRrecovery effects, such as spontaneous recovery, may be due to changes in the background or temporal context that follow extinction, resulting in an inability to retrieve the extinction memory. The extinction cue in the present experiments may have reduced spontaneous recovery by retrieving an otherwise less accessible saccharin-no illness association (see Bouton, 1993, 1994). The extinction cue effects on spontaneous recovery and renewal in appetitive conditioning (Brooks \& Bouton, 1993, 1994) have been explained similarly (Bouton, 1993; see Spear, 1978). This account suggests some degree of modulatory control over consumption of saccharin by the extinction cue at the time of testing. This suggesion is particularly interesting given that the extinction cue was an auditory stimulus. Considerable previous research, combined with findings in the present study, suggest that there are constraints on the degree to which auditory cues enter into direct excitatory or inhibitory associations with the US in CTA (e.g., Garcia \& Koelling, 1966; as described above, the failed tests for conditioned inhibition to the cue and the lack of discriminative control over saccharin consumption by the cue during conditioning and extinction in Experiments 1 and 3). However, the extinction cue's effect on spontaneous recovery suggests that under some circumstances (e.g., following retention intervals introduced after extinction), an auditory stimulus in CTA may function by modulating a CS-no-US association.

During testing in Experiment 3, the saccharin aversion remained strongest in the presence of the conditioning cue. This finding could also be incorporated into a memory retrieval view if that cue helped to retrieve the CS-US association from conditioning. On this view, the conditioning cue may have served as a modulator akin to a positive occasion setter or contextual stimulus (e.g., Bouton, 1993; Holland, 1992). This possibility is noteworthy for several reasons. At the time of testing, the conditioning cue may have aided retrieval of a relatively weak saccharin-illness conditioning memory. Compared with other conditioning methods, extinction in CTA may result in a ratio of CSno-US memory retrieval strength to CS-US memory retrieval strength that is larger for a longer period of time and/or across physical contexts following extinction. The CS-no-US memory may still substantially, but not completely, interfere with CS-US memory retrieval at the end of the 18-day retention interval used in existing demonstrations of spontaneous recovery in CTA (Rosas \& Bouton, 1996; the present Experiments 1-3). The conditioning cue may have reduced this interference during testing and promoted recovery. This could help explain why uncued performance to the CS in existing CTA spontaneous recovery tests is notably reduced compared with that commonly reported with other conditioning methods (e.g., Bouton \& Brooks, 1993; Brooks \& Bouton, 1993; Robbins, 1990). (Retention interval duration and other factors may also be important.) This account could also help explain other CTA results such as comparatively weak renewal (e.g., Rosas \& Bouton, 1997) and variable success in demonstrating reinstatement (see Bouton, 1982; Schachtman, Brown, \& Miller, 1985). It is also consistent with reports that extinction in CTA may endow an extinguished taste with conditioned inhibitory properties (e.g., Carlton, Mitchell, \& Schachtman, 1996). The conditioning cue's effect on spontaneous recovery is also interesting because it may parallel the effect of auditory cues used in pigeon autoshaping that are effective positive modulators but poor CSs (e.g., Rescorla, 1985). Finally, if the conditioning cue enhanced the saccharin aversion through a modulatory mechanism, its effect during testing may have been to add the renewal effect to spontaneous recovery (e.g., Rosas \& Bouton, 1997, 1998). Future research will help to determine whether the conditioning cue prolonged spontaneous recovery through modulation or through another mechanism, such as compound conditioning or configural cue learning (e.g., Durlach \& Rescorla, 1980; Mackintosh, 1971; Rescorla, 1973; Rescorla \& Wagner, 1972; Wagner, 1981), potentiation (e.g., Best, Batson, Meachum, Brown, \& Ringer, 1985; Ellins \& von Kluge, 1987; Slotnick, Westbrook, \& Darling, 1997), or marking (e.g., Lieberman, Davidson, \& Thomas, 1985).

The overall pattern of findings with the extinction cue is consistent with Bouton's (1993) retrieval view of spontaneous recovery as it applies to taste-aversion learning. Spontaneous recovery may occur because of a failure to retrieve a saccharin-no-illness extinction memory. The extinction cue may retrieve that memory and reduce spontaneous recovery. Together with extinction cue studies in appetitive conditioning, the present findings suggest that similar memory processes may contribute to spontaneous recovery in both appetitive and aversive motivational systems.

\section{REFERENCES}

ArCher, T., SJödÉn, P. O., \& Nilsson, L.-G. (1985). Contextual control of taste-aversion conditioning and extinction. In P. D. Balsam \& A. Tomie (Eds.), Context and learning (pp. 225-271). Hillsdale, NJ: Erlbaum.

BEST, M. R. (1975). Conditioned and latent inhibition in taste-aversion learning: Clarifying the role of learned safety. Journal of Experimental Psychology: Animal Behavior Processes, 1, 97-113.

Best, M. R., Batson, J. D., Meachum, C. L., Brown, E. R., \& RINGER, M. (1985). Characteristics of taste-mediated environmental potentiation in rats. Learning \& Motivation, 16, 190-209

Best, M. R., Dunn, D. P., Batson, J. D., Meachum, C. L., \& Nash, S. M. (1985). Extinguishing conditioned inhibition in flavouraversion learning: Effects of repeated testing and extinction of the excitatory element. Quarterly Journal of Experimental Psychology, 37, 359-378.

Bouton, M. E. (1982). Lack of reinstatement of an extinguished taste aversion. Animal Learning \& Behavior, 10, 233-241. 
Bouton, M. E. (1991). Context and retrieval in extinction and in other examples of interference in simple associative learning. In L. Dachowski \& C. F. Flaherty (Eds.), Current topics in animal learning. Brain, emotion, and cognition (pp. 25-53). Hillsdale, NJ: Erlbaum.

Bouton, M. E. (1993). Context, time, and memory retrieval in the interference paradigms of Pavlovian learning. Psychological Bulletin, 114, 80-99.

Bouton, M. E. (1994). Context, time, and ambiguity in Pavlovian conditioning. Current Directions in Psychological Science, 3, 49-53.

Bouton, M. E., \& BrooKs, D. C. (1993). Time and physical context effects in a Pavlovian discrimination reversal. Journal of Experimental Psychology: Animal Behavior Processes, 19, 165-179.

Brooks, D. C. (in press). Local and remote extinction cues reduce spontaneous recovery. Quarterly Journal of Experimental Psychology.

Brooks, D. C., \& Bouton, M. E. (1993). A retrieval cue for extinction attenuates spontaneous recovery. Journal of Experimental Psychology: Animal Behavior Processes, 19, 77-89.

Brooks, D. C., \& Bouton, M. E. (1994). A retrieval cue for extinction attenuates response recovery (renewal) caused by a return to the conditioning context. Journal of Experimental Psychology: Animal Behavior Processes, 20, 366-379.

Brooks, D. C., \& Neves, J. L. (1998). Counterconditioned extinction cues reduce spontaneous recovery: Evaluation of contextual control, occasion setting, and the erasure effect. Unpublished manuscript.

Burdick, C. K., \& JAMES, J. P. (1970). Spontaneous recovery of conditioned suppression of licking by rats. Journal of Comparative \& Physiological Psychology, 72, 467-470.

Carlton, J. L., Mitchell, K. G., \& Schachtman, T. R. (1996). Conditioned inhibition produced by extinction of a conditioned stimulus. Learning \& Motivation, 27, 335-361

Cunningham, C. L. (1981). Association between the elements of a bivalent compound stimulus. Journal of Experimental Psychology: Animal Behavior Processes, 7, 425-436.

Delamater, A. R., Kruse, J. M., Marlin, S., \& LoLordo, V. M. (1986). Conditioned inhibition in taste aversion learning: Testing methodology and empirical status. Animal Learning \& Behavior, 14, 6-14.

Durlach, P. J., \& Rescorla, R. A. (1980). Potentiation rather than overshadowing in flavor-aversion learning: An analysis in terms of within-compound associations. Journal of Experimental Psychology: Animal Behavior Processes, 6, 175-187.

Ellins, S. R., \& von Kluge, S. (1987). Preexposure and extinction effects of lithium chloride induced taste-potentiated aversions for spatially contiguous auditory food cues in rats. Behavioral Neuroscience, 101, 164-169.

Ellson, D. G. (1939). Spontaneous recovery of the galvanic skin response as a function of the recovery interval. Journal of Experimental Psychology, 25, 586-600.

GARCIA, J. (1989). Food for Tolman: Cognition and cathexis in concert. In T. Archer \& L. G. Nilsson (Eds.), Aversion, avoidance, and anxiety: Perspectives on aversively motivated behavior (pp. 45-85). Hillsdale, NJ: Erlbaum.

Garcia, J., Hankins, W. G., \& Rusiniak, K. W. (1974). Behavioral regulation of the milieu interne in man and rat. Science, 185, 824-831.

Garcia, J., \& Koelling, R. A. (1966). Relation of cue to consequence in avoidance learning. Psychonomic Science, 4, 123-124.

Holland, P. C. (1981). Acquisition of representation-mediated conditioned food aversions. Learning \& Motivation, 12, 1-18.

Holland, P. C. (1989). Transfer of negative occasion setting and conditioned inhibition across conditioned and unconditioned stimuli. Journal of Experimental Psychology: Animal Behavior Processes, $15,311-328$

Holland, P. C. (1992). Occasion setting in Pavlovian conditioning. In D. L. Medin (Ed.), The psychology of learning and motivation (Vol. 29, pp. 69-125). San Diego: Academic Press.

Howell, D. C. (1987). Statistical methods for psychology (2nd ed.). Boston: PWS-Kent.

Kraemer, P. J., \& Spear, N. E. (1992). The effect of nonreinforced stimulus exposure on the strength of a conditioned taste aversion as a function of retention interval: Do latent inhibition and extinction involve a shared process? Animal Learning \& Behavior, 20, I-7.

LEwIS, D. J. (1956). Acquisition, extinction, and spontaneous recovery as a function of percentage of reinforcement and intertrial intervals. Journal of Experimental Psychology, 51, 45-53.

Lieberman, D. A., Davidson, F. H., \& Thomas, G. V. (1985). Marking in pigeons: The role of memory in delayed reinforcement. Journal of Experimental Psychology: Animal Behavior Processes, 11, 61 l-624.

MACKINTOSH, N. J. (1971). An analysis of overshadowing and blocking. Quarterly Journal of Experimental Psychology, 23, 118-125.

MaCkintosh, N. J. ( 1975). A theory of attention: Variations in the associability of stimuli with reinforcement. Psychological Review, 82 , 276-298

Pavlov, I. P. (1927). Conditioned reflexes (G. V. Anrep, Trans.). London: Oxford University Press.

Pearce, J. M. (1987). A model for stimulus generalization in Pavlovian conditioning. Psychological Review, 94, 61-73.

Pearce, J. M., \& Hall, G. (1980). A model for Pavlovian learning: Variations in the effectiveness of conditioned but not of unconditioned stimuli. Psychological Review, 87, 532-552.

Puente, G. P., Cannon, D. S., Best, M. R., \& Carrell, L. E. (1988). Occasion setting of fluid ingestion by contextual cues. Learning \& Motivation, 19, 239-253.

Rescorla, R. A. (1969). Pavlovian conditioned inhibition. Psychological Bulletin, 72, 77-94.

RESCORLA, R. A. (1973). Evidence for "unique stimulus" account of configural conditioning. Journal of Comparative \& Physiological Psychology, 85, 331-338.

RESCORLA, R. A. (1979). Conditioned inhibition and extinction. In A. Dickinson \& R. A. Boakes (Eds.), Mechanisms of learning and motivation: A memorial volume to Jerzy Konorski (pp. 83-110). Hillsdale, NJ: Erlbaum.

Rescorla, R. A. (1985). Conditioned inhibition and facilitation. In R. R. Miller \& N. E. Spear (Eds.), Information processing in animals: Conditioned inhibition (pp. 299-326). Hillsdale, NJ: Erlbaum.

Rescorla, R. A. (1997). Spontaneous recovery after Pavlovian conditioning with multiple outcomes. Animal Learning \& Behavior, 25, 99-107.

Rescorla, R. A., \& Cunningham, C. L. (1978). Recovery of the US representation over time during extinction. Learning \& Motivation, 9, 373-391.

Rescorla, R. A., \& Wagner, A. R. (1972). A theory of Pavlovian conditioning: Variations in the effectiveness of reinforcement and nonreinforcement. In A. H. Black \& W. F. Prokasy (Eds.), Classical conditioning II: Current research and theory (pp. 64-99). New York: Appleton-Century-Crofts.

RoBBiNs, S. J. (1990). Mechanisms underlying spontaneous recovery in autoshaping. Journal of Experimental Psychology: Animal Behavior Processes, 16, 235-249.

RosaS, J. M., \& Bouton, M. E. ( 1996). Spontaneous recovery after ex tinction of a conditioned taste aversion. Animal Learning \& Behavior, 24, 341-348.

Rosas, J. M., \& Bouton, M. E. (1997). Renewal of a conditioned taste aversion upon return to the conditioning context after extinction in another one. Learning \& Motivation, 28, 216-229.

Rosas, J. M., \& Bouton, M. E. (1998). Context change and retention interval can have additive, rather than interactive, effects in taste aversion learning. Psychonomic Bulletin \& Review, 5, 79-83.

Rozin, P., \& Kalat, J. W. (1971). Specific hungers and poison avoidance as adaptive specializations of learning. Psychological Review, 78, 459-486.

Schachtman, T. R., Brown, A. M., \& Miller, R. R. (1985). Reinstatement-induced recovery of a taste- $\mathrm{LiCl}$ association following extinction. Animal Learning \& Behavior, 13, 223-227.

Slotnick, B. M., Westbrook, F., \& Darling, F. M. C. (1997). What the rat's nose tells the rat's mouth: Long delay aversion conditioning with aqueous odors and potentiation of taste by odors. Animal Learning \& Behavior, 25, 357-369.

SPEAR, N. E. (1978). The processing of memories: Forgetting and retention. Hillsdale, NJ: Erlbaum.

Thomas, D. R., \& Sherman, L. (1986). An assessment of the role of handling cues in spontaneous recovery after extinction. Journal of the Experimental Analysis of Behavior, 46, 305-314

WAGNER, A. R. (1981). SOP: A model of automatic memory processing 
in animal behavior. In N. E. Spear \& R. R. Miller (Eds.), Information processing in animals: Memory mechanisms (pp. 5-47). Hillsdale, NJ: Erlbaum.

\section{NOTE}

1. With the present procedures, the auditory cue may appear identical to contextual stimuli (e.g., apparatus cues provided by odors, chamber walls, and grid floors, etc.) because it was presented throughout each saccharin extinction session. However, there may be functional differences between diffuse background contextual stimuli that control, for example, the renewal effect (e.g., Bouton, 1993) and cues presented during extinction that then reduce spontaneous recovery. For example, in several unpublished appetitive conditioning experiments (Brooks \&
Neves, 1998), we have found that a counterconditioned extinction cue strongly reduces spontaneous recovery. This effect is more analogous to that of a counterconditioned serial negative feature (e.g., Holland, 1989) than to that of background contextual stimuli that have been paired with the US following extinction of the CS, a procedure that typically produces reinstatement (i.e., a CR increase, rather than the $\mathrm{CR}$ decrease we find with the counterconditioned cue). Because possible functional and theoretical distinctions may be made, at present we prefer the term "extinction cue" for the auditory cue used here over the broader term "contextual stimulus."

(Manuscript received June 12, 1998; revision accepted for publication September 5, 1998.) 